\title{
METODE PERHITUNGAN ANGKA INDEKS \\ PRODUKTIVITAS MENGGUNAKAN \\ MODEL MARVIN E MUNDEL
}

\author{
Haryadi Sarjono ${ }^{1}$
}

\begin{abstract}
There are several measures and methods to basically perform the productivity of calculation. Marvin E Mundel (1978) methods uses calculation approach index number, which is amount that shows the difference change of time between basic period and actual period. The result can be decrease, stabil, or increase.
\end{abstract}

Keywords: productivity, index

\section{ABSTRAK}

Terdapat beberapa ukuran dan metode untuk menunjukkan perhitungan produktivitas. Metode Marvin E. Mundel menggunakan pendekatan metode perhitungan angka indeks produktivitas, yaitu jumlah yang menunjukkan perubahan mendasar dalam kurun waktu atau periode tertentu terhadap suatu masalah. Hasilnya dapat menurun, stabil, atau meningkat.

Kata kunci: produktivitas, indeks

1 Staf Pengajar Fakultas Ekonomi, UBiNus, Jakarta 


\section{PENDAHULUAN}

Dalam keadaan ekonomi yang makin memprihatinkan banyak perusahaan pabrikasi (khususnya sektor riil) menjadi terpuruk. Mereka tidak lagi mengandalkan profit atau laba perusahaan tetapi hanya mengandalkan survive perusahaan saja. Untuk menjadi perusahaan yang survive, harus dilakukan efisiensi di segala bidang.

Perhitungan produktivitas model Marvin E Mundel (1978) mendasarkan pada angka indeks yang merupakan besaran dan menunjukkan perubahan mendasar dalam kurun waktu atau periode tertentu terhadap suatu masalah.

\section{PEMBAHASAN}

\section{Konsep Dasar}

\section{Efisiensi (Doing the Things Rigths)}

Efisiensi umumnya berhubungan dengan masukan (input), misalnya berdasarkan standar, ditetapkan tingkat output adalah 300 unit/jam/tenaga kerja. Seorang operator mesin yang bernama Pak Joni hanya mampu menghasilkan 200 unit/jam. Dalam hal ini tingkat efisiensi dari Pak Joni adalah sebagai berikut. Efisiensi = performansi aktual Pak Joni/standar yang ditetapkan, yaitu 200/300 = 0,75 atau 75\%. Dengan demikian agar dapat meningkatkan efisiensi tenaga kerja (operator), keterampilan Pak Joni dalam mengoperasikan mesin perlu ditingkatkan.

\section{Efektivitas (Doing the Right Rigths)}

Efektivitas umumnya berhubungan dengan output (keluaran). Misalnya berdasarkan rencana pada bulan Juni 1999, pabrik XYZ akan memproduksi 2000 unit output . Setelah proses produksi berlangsung diketahui output aktual yang dihasilkan pabrik hanya 1600 unit. Efektivitas $=$ output aktual $/$ output rencana $=1600 / 2000=0,8$ atau $80 \%$.

Kadang-kadang orang salah menyebutkan antara efisiensi dengan efektivitas. Dalam persoalan di atas sering dikatakan efisiensi perusahaan hanya 80\% turun sebanyak 20\% dibandingkan target.

\section{Produktivitas}

Apabila ukuran keberhasilan produksi selama ini hanya dipandang dari sisi output saja maka produktivitas dipandang dari dua sisi sekaligus, yaitu sisi input dan output. Dengan demikian, dapat dikatakan produktivitas berkaitan dengan efisiensi penggunaan input dalam memproduksi output (barang atau jasa).

Produktivitas $=$ output yang dihasilkan input yang dihasilkan 


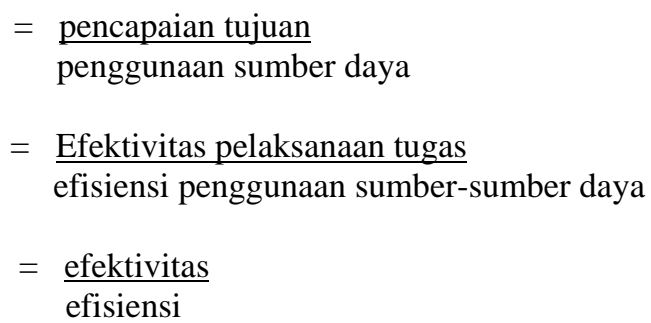

\section{Metode Perhitungan}

Pada dasarnya, perhitungan angka indeks merupakan besaran yang menunjukkan perbedaan perubahan dalam waktu atau ruang mengenai hal tertentu. Seperti diketahui bersama bahwa angka indeks telah menjadi patokan untuk menghitung besarnya angka inflasi di Indonesia, yaitu indeks harga (konsumen) yang digunakan untuk mengukur perubahan harga sepanjang periode tertentu. Selain indeks harga juga dikenal indeks produksi yang digunakan untuk mengukur perubahan produksi perusahaan penghasil produk barang secara fisik. Untuk menghitung angka indeks maka harus ada periode tahun dasar atau periode waktu dasar tertentu sebagai pedoman atau patokan membandingkan angka indeks, tahun atau waktu yang akan kita hitung nantinya. Hasilnya, apakah naik, stabil, atau menurun.

Tabel 1 Contoh Menghitung Indeks Harga (Konsumen) (Sadono Sukirno, 1994)

\begin{tabular}{cccccc}
\hline $\begin{array}{l}\text { Kelompok } \\
\text { barang }\end{array}$ & Weight & Tahun dasar & (1980) & Tahun (1993) \\
& & Harga (Rp) & Harga $\mathrm{x}$ & Harga Rp & Harga $\mathrm{X}$ \\
\hline \hline A & 50 & 1,000 & 50,000 & 2,000 & 100,000 \\
$\mathrm{~B}$ & 20 & 5,000 & 100,00 & 11,000 & 220,000 \\
$\mathrm{C}$ & 5 & 5,000 & 25,000 & 16,000 & 80,000 \\
$\mathrm{D}$ & 25 & 3,000 & 75,000 & 8,000 & 200,000 \\
\hline & 100 & & 250,00 & & 600,000 \\
\hline
\end{tabular}

Tahun 1980 adalah tahun dasar atau tahun patokan. Indeks harga tahun dasar 1980 adalah =100 (digunakan angka 100 adalah asumsi saja untuk mempermudah perhitungan nantinya). Indesks harga tahun 1993=(Rp $600.00 /$ Rp 250.000)*100 =240. Dengan demikian antara tahun 1980 dan 1993 harga telah meningkat sebanyak 140\% (dari 240-100).

Metode Marvin E. Mundel (1978) memperkenalkan penggunaan angka indeks produktivitas pada tingkat perusahaan berdasarkan tiga bentuk pengukuran sebagai berikut.

- $\quad P=\frac{\text { (jumlah AOPm / jumlah RIPm) }}{\text { (jumlah }}$ (jumlah $\mathrm{AOPb} /$ jumlah RIPb) 
- $\quad \mathrm{P}=$ (jumlah AOPm / jumlah AOPb)

(jumlah RIPm / jumlah RIPb)

- $\quad \mathrm{P}=(\mathrm{AOP} 1 \mathrm{~m}+\mathrm{AOP} 2 \mathrm{~m} / \mathrm{RiP} 1 \mathrm{~m}+\mathrm{RiP} 2 \mathrm{~m}+\mathrm{RiP} 3 \mathrm{~m})$

(AOP 1b + AOP 2b / RiP 1b + RiP 2b +RiP 3b)

$\mathrm{AOP}=$ agregat output partil

RIP = resource input partial

$\mathrm{b} \quad=$ tahun dasar

m =periode liputan ( pengukuran)

RiP 1 = input partial dari Capital cost

RiP 2 =input partial dari energi peralatan buruh langsung

RiP $3=$ input partial dari buruh tidak langsung

AOP 1 = output partial dari dari nilai Capital langsung

AOP 2 = output partial dari biaya buruh langsung

AOP 3 = output partial dari biaya buruh tidak langsung

Sebagai cotoh penerapan model Mundel, ada data perusahaan XYZ yang tediri dari periode waktu seperti di bawah ini.

Tabel 2 Data Input dan Output PT XYZ

(Vincent Gaspers, 1998)

\begin{tabular}{rlll}
\hline No. & Keterangan & Tahun 1980 (periode dasar) & Tahun 1998 \\
\hline \hline 1. & Total output & 3000 unit & 4000 unit \\
\hline 2. & Jam tenaga kerja langsung & 6000 unit & 9000 unit \\
\hline 3. & Gaji tenaga kerja langsung & Rp.130 juta & Rp.149,5 juta \\
\hline 4. & Depresiasi modal & Rp.39 juta & Rp. 45,5 juta \\
\hline 5. & Nilai buku modal & Rp. 117 juta & Rp.234 juta \\
\hline 6. & Biaya total langsung & Rp.195 juta & Rp 247 juta \\
\hline 7. & Biaya total keseluruhan & Rp.260 juta & Rp. 344,5 juta \\
\hline 8. & Jumlah energi & $1000 \mathrm{kw}$ & $1200 \mathrm{kw}$ \\
\hline 9. & Material & $9000 \mathrm{~kg}$ & $13000 \mathrm{~kg}$ \\
\hline
\end{tabular}

Di dalam data tersebut (Tabel 2), apabila ada item lainnya yang perlu ditambahkan atau dikurangi dapat dapat dikonversikan ke dalam satuan moneter (nilai uang) atau satuan fisik lainnya (kg, kw, jam, dan lain-lainnya). Perhitungan akan menggunakan rumus Mundel yang kedua tetapi rumus Mundel yang pertama dan ketiga dapat digunakan sebagai alternatif lain (ketiga-tiganya menghasilkan angka yang sama).

- $\quad$ Indeks Produktivitas Tenaga Kerja

$$
\begin{aligned}
\mathrm{P} & =((\mathrm{AOPm} / \mathrm{AOPb}) /(\mathrm{RIPm} / \mathrm{RIPb}) * 100 \\
& =(((4000 / 3000) /(9000 / 6000)) * 100 \\
& =88.89
\end{aligned}
$$


Berarti angka indeks produktivitas tenaga kerja periode 1998 menurun, yaitu 100\% sebesar 11,11 (100-88,89) dibandingkan periode dasar ( tahun 1980) yaitu 100.

- $\quad$ Indeks Produktivitas Gaji Tenaga Kerja Langsung

$\mathrm{P}=((\mathrm{AOPm} / \mathrm{AOPb}) /(\mathrm{RIPm} / \mathrm{RIPb}) * 100$

$=((4000 / 3000) /(149,5 / 130)) * 100$

$=115,94$ berarti angka indeks produktivitas gaji tenaga kerja langsung periode 1998

naik sebesar $15,94 \%(115,94-100)$ dibanding periode dasar ( tahun 1980) yaitu

100 .

- $\quad$ Indeks Produktivitas Depresiasi Modal

$\mathrm{P}=((4000 / 3000) /(149,5 / 130)) * 100$

$=114,29$ berarti angka indeks produktivitas depresi modal periode 1998 naik 4,29

\% q $(114,29$ - 100) dibanding periode dasar (tahun 1980) yaitu 100

- $\quad$ Indeks Produktivitas Nilai Buku Modal

$\mathrm{P}=((4000 / 3000) /(45,5 / 39)) * 100$

= 66,65 berarti angka indeks produktivitas nilai buku modal periode 1998 menurun sebesar 33,35 \% (100 - 66,5) dibandingkan periode dasar ( tahun 1980) yaitu 100 .

- $\quad$ Indeks Produktivitas Biaya Total Langsung

$\mathrm{P}=((4000 / 3000) /(247 / 195)) * 100$

$=105,24$ berarti angka indeks produktivitas biaya total langsung periode 1998 hanya sebesar 5,24 \% (105,24 - 100) dibandingkan periode dasar ( tahun 1980 ) yaitu 100.

- Indeks Produktivitas Biaya Total Keseluruhan

$\mathrm{P}=((4000 / 3000) /(344,5 / 260)) * 100$

$=100,60$ berarti angka indeks produktivitas nilai buku modal periode 1998 hanya naik kecil sekali yaitu 0,60 \% (100,60 - 100) dibandingkan periode dasar ( tahun 1980 ) yaitu 100

- $\quad$ Indeks Produktivitas Energi

$\mathrm{P}=((4000 / 3000) /(1200 / 1000)) * 100$

$=111,08$ berarti angka indeks produktivitas energi periode 1998 naik sebesar 11,08 \% (111,08 - 100) dibandingkan periode dasar ( tahun 1980 ) yaitu 100.

- $\quad$ Indeks Produktivitas Material

$\mathrm{P}=((4000 / 3000) /(13000 / 9000)) * 100$ 
= 92,86 berarti angka indeks produktivitas material periode 1998 menurun sebesar $7.14 \%(100$ - 92,86) dibandingkan periode dasar ( tahun 1980 ) yaitu 100 .

Tabel 3 Indeks Produktivitas PT XYZ

\begin{tabular}{llccc}
\hline $\begin{array}{l}\text { No } \\
.\end{array}$ & Keterangan & $\begin{array}{c}\text { Tahun } 1980 \\
\text { (periode dasar) }\end{array}$ & Tahun 1998 & Perubahan \\
\hline \hline 1 & Tenaga kerja langsung & 100 & 88.9 & turun 11,11\% \\
\hline 2 & Gaji tenaga kerja & 100 & 115.94 & naik 15,94\% \\
\hline 3 & Depresiasi & 100 & 114.29 & naik 14,29\% \\
\hline 4 & Nilai buku & 100 & 66.65 & turun 33,35\% \\
\hline 5 & Biaya total & 100 & 105.24 & naik 5,24 \% \\
\hline 6 & Biaya total keseluruhan(langsung+tidak) & 100 & 100.6 & naik 0,60\% \\
\hline 7 & Jumlah energi & 100 & 111.08 & naik $11,08 \%$ \\
\hline 8 & Materia & 100 & 92.86 & naik 7,14\% \\
\hline
\end{tabular}

Catatan:

1. Angka indeks tahun dasar diasumsikan $=100$

2. Apabila indeks angka tahun pengukuran lebuh dari 100, berarti ada peningkatan (naik) dibandingkan tahun dasar.

3. Apabila indeks angka tahun pengukuran kurang dari 100, berarti ada penurunan produktivitas dibandingkan tahun dasar.

\section{PENUTUP}

\section{Simpulan}

1. Dari hasil perhitungan model Marvin E . Mundel (1978) terlihat ada beberapa data input jumlah kuantitasnya naik (dibandingkan periode dasar) tetapi produktivitas relatif menurun antara lain sebagai berikut.
a. Jam tenaga kerja langsung turun $11,11 \%$
b. Nilai buku modal turun $33,35 \%$
c. Material turun $7,14 \%$

2. Selain data input di atas, ada juga data input lainnya yang jumlah kuantitasnya meningkat tetapi produktivitasnya juga meningkat antara lain sebagai berikut.
a. Gaji tenaga kerja langsung naik $15,94 \%$
b. Depresiasi modal naik $14,29 \%$
c. Biaya total langsung naik $5,24 \%$
d. Biaya total keseluruhan naik $0,60 \%$
e. Jumlah energi naik $11,08 \%$ 
3. Dari hasil perhitungan telihat nilai buku modal mengalami penurunan yang cukup drastis sebanyak 33,35 \%. Hal itu sebaiknya menjadi perhatian pihak manejemen perusahaan agar diambil tindakan perbaikan sehingga pada periode berikutnya input dari nilai buku modal dapat meningkat produktivitasnya.

\section{DAFTAR PUSTAKA}

Gaspersz, Vincent. 1998. Produktivitas Total dalam Bisnis Globalisasi. Jakarta: Gramedia.

Herjanto, Eddy. 1997. Manajemen Produksi dan Operasi. Jakarta: Grasindo.

Sukirno, Sadono. 1994. Pengantar Makro Ekonomi. Jakarta: Raja-Grafiti.

Tamit, Zulian. 1996. Manajemen Produksi dan Operasi. Cetakan Pertama. Yogyakarta: Ekonisia, UII. 